\title{
PENGARUH PENGALAMAN HUKUMAN FISIK DAN JENIS KELAMIN TERHADAP MITOS DAN INTENSI PENGGUNAAN HUKUMAN FISIK PADA REMAJA
}

\author{
Maya Damayanti $\left.{ }^{1 *}\right)$, Efriyani Djuwita ${ }^{1}$
}

${ }^{1}$ Fakultas Psikologi, Universitas Indonesia, Depok 16424, Indonesia

*)E-mail: maya.damayanti91@ui.ac.id

\begin{abstract}
Abstrak
Banyak orang tua memercayai hukuman fisik tepat digunakan sebagai strategi yang efektif untuk mendisiplinkan anak sehingga membuat siklus penerapan hukuman fisik tidak terputus pada generasi selanjutnya. Penelitian ini bertujuan untuk menganalisis pengaruh pengalaman menerima hukuman fisik dan perbedaan jenis kelamin terhadap penerimaan mitos dan intensi menggunakan hukuman fisik pada remaja. Penelitian ini menggunakan pendekatan kuantitatif dengan teknik purposive sampling yang melibatkan 123 remaja berusia 13-17 tahun dengan status sosial ekonomi menengah ke bawah dan berdomisili di Jawa Barat. Pengalaman hukuman fisik diukur menggunakan Parent-Child Conflict Tactic Scale (CTSPC) dan penerimaan mitos hukuman fisik diukur menggunakan Corporal Punishment Myth Scale (CPMS). Uji analisis jalur menunjukkan bahwa perbedaan jenis kelamin secara signifikan $(\beta=-5,306 ; p<0,05)$ berpengaruh pada penerimaan mitos hukuman fisik dengan hasil remaja laki-laki memiliki penerimaan mitos hukuman fisik yang lebih tinggi dibandingkan remaja perempuan. Sedangkan pengalaman hukuman fisik tidak memengaruhi penerimaan mitos hukuman fisik pada remaja. Hasil analisis jalur juga menunjukkan bahwa mitos hukuman fisik berpengaruh terhadap intensi penggunaan hukuman fisik. Hasil penelitian dapat digunakan untuk memahami alasan tidak terputusnya siklus hukuman fisik dan dapat membantu praktisi dalam pembuatan modul parenting terkait strategi disiplin.
\end{abstract}

Kata kunci: hukuman fisik, jenis kelamin remaja, mitos, remaja, strategi disiplin

\section{The Effect of the Corporal Punishment Experience and Gender on Adolescent Myth and Intentions of Corporal Punishment}

\begin{abstract}
Many parents have adopted corporal punishment as an effective strategy to discipline their children and make the cycle of corporal punishment unbroken in the next generation. The study aimed to analyze the role of corporal punishment experience and gender differences toward corporal punishment myths and intentions using corporal punishment in adolescents. The purposive sampling technique was used to obtain 123 participants aged 13-17 years with middle to lower socioeconomic status and domiciled in West Java. The experience of corporal punishment was measured using the Parent-child Conflict Tactic Scale (CTSPC) and the acceptance of corporal punishment myth was measured using the Corporal Punishment Myth Scale (CPMS). The path analysis test showed that gender differences significantly affected the acceptance of the corporal punishment myth $(\beta=-5,306$, $p<0,05$ ) that boys had higher acceptance of corporal punishment myth than girls. Meanwhile, corporal punishment experience did not significantly influence the acceptance of the corporal punishment myth in adolescents. The path analysis test also showed that corporal punishment myth significantly affected the intension using corporal punishment. The results of this research may be used to understand the reasons for the continuous use of corporal punishment and assist practitioners in making parenting modules related to disciplinary strategies.
\end{abstract}

Keywords: adolescents, adolescent's gender, corporal punishment, myth, parental discipline

\section{PENDAHULUAN}

Corporal punishment (hukuman fisik) merupakan penggunaan kekuatan fisik dengan tujuan menyebabkan rasa sakit namun tidak menimbulkan cedera pada tubuh, hal ini dilakukan untuk mengoreksi atau mengontrol perilaku anak (Straus, 2010). Hasil penelitian yang dilakukan oleh Fréchette dan Romano
(2017) menjelaskan terdapat beberapa perilaku strategi disiplin yang dianggap sebagai hukuman fisik oleh orang tua seperti memukul, menampar area badan (tangan, lengan, kaki), menampar area wajah (muka, mulut, kepala, telinga), mendorong, mencubit, memukul dengan benda (sabuk, tongkat), mencuci mulut dengan sabun, atau mengoleskan sambal ke lidah anak. Penggunaan hukuman fisik sebagai strategi disiplin dapat terjadi karena masih ada 
orang tua yang menganggap hukuman fisik tepat digunakan untuk mendidik anak selama tidak mencederai anak dan ada pula orang tua yang tidak menyadari bahwa strategi disiplin yang digunakan merupakan bentuk dari hukuman fisik sehingga perilaku tersebut terus diulang (Fréchette \& Romano, 2017). Selain itu, penelitian yang dilakukan oleh Bornstein (2013) dan Chiocca (2017) menjelaskan salah satu faktor yang dapat memengaruhi dukungan terhadap penggunaan hukuman fisik adalah adanya keyakinan (mitos) bahwa hukuman fisik merupakan sesuatu yang normatif atau sesuai dengan norma yang berlaku di kalangan masyarakat.

Mitos merupakan suatu sistem kepercayaan yang dapat membantu individu memahami dunia di sekitarnya dan berfungsi untuk membangun hubungan sebab-akibat antara fenomena yang terjadi dalam kehidupan seharihari (Furnham, 2005). Pada kasus penggunaan hukuman fisik sebagai strategi disiplin orang tua, mitos dikatakan memiliki andil yang membuat penggunaan hukuman fisik tidak terputus hingga generasi selanjutnya. Penelitian yang dilakukan Kish dan Newcombe (2015) serta Watakakosol et al. (2019) terkait mitos hukuman fisik menunjukkan individu yang memiliki tingkat kepercayaan yang tinggi pada mitos hukuman fisik cenderung menggunakan hukuman fisik sebagai strategi disiplin ketika mengalami konflik dengan anak. Adapun beberapa mitos yang dipercaya oleh masyarakat terkait penggunaan hukuman fisik adalah dapat mendisiplinkan anak, membuat anak langsung patuh pada orang tua, mendukung perkembangan moral anak, serta menjaga anak agar selalu rendah hati, dan bertanggung jawab (Wonde et al., 2014).

Penelitian terkait mitos hukuman fisik masih terbilang baru dan belum banyak diteliti (Kish \& Newcombe, 2015; Watakakosol et al., 2019). Oleh karena itu, pada penelitian ini peneliti berusaha untuk menyelidiki faktor-faktor yang dapat memengaruhi penerimaan terkait mitos hukuman fisik yang membuat siklus penggunaan hukuman fisik tidak terputus hingga saat ini di Indonesia. Penelitian ini diperkuat oleh data di bulan Juni 2020 dari sistem informasi daring perlindungan perempuan dan anak yang mengungkapkan terdapat 3.935 kasus terkait kekerasan terhadap anak dan angka ini akan terus bertambah setiap harinya (Kemen PPPA, 2020). Salah satu laporan yang banyak diterima merupakan kasus kekerasan fisik dengan jumlah pengaduan sebanyak 1.320 kasus. Data tersebut juga memperlihatkan, dari 3.935 kasus pengaduan yang diterima, sebanyak 1.259 kasus kekerasan dialami oleh anak berusia 13 sampai 17 tahun (Kemen PPPA, 2020).

Lebih lanjut, data ini didukung oleh hasil survei terbaru yang dilakukan oleh Yougov (Ho, 2019) kepada 1.231 orang tua. Dari penelitian tersebut ditemukan bahwa 73 persen orang tua di Indonesia masih menerapkan hukuman fisik di rumah dan lebih dari setengah orang tua berpikir bahwa hukuman fisik terkadang perlu diberikan kepada anak. Penelitian yang dilakukan oleh Maryam (2017) menunjukkan kekerasan fisik yang dialami oleh anak cukup tinggi, adapun alasan untuk mendisiplinkan anak merupakan penyebab paling tinggi orang tua melakukan tindakan tersebut (Wati \& Puspitasari, 2018). Berdasarkan data-data tersebut, dapat disimpulkan bahwa masih banyak orang tua di Indonesia yang beranggapan bahwa penggunaan hukuman fisik merupakan strategi yang efektif dalam mendisiplinkan anak.

Peneliti menduga bahwa penerimaan mitos hukuman fisik dapat dipengaruhi oleh pengalaman anak menerima hukuman fisik dari orang tua. Peneliti berasumsi, anak yang terpapar dengan hukuman fisik akan melakukan proses pembelajaran dan membentuk pola pikir bahwa hukuman fisik adalah hal benar untuk dipraktikan. Asumsi ini diperkuat oleh hasil penelitian kualitatif yang dilakukan oleh Breen, Daniels, dan Tomlinson (2015) kepada remaja terkait pengalaman mereka terpapar kekerasan yang menunjukkan fakta bahwa anak yang pernah mendapatkan hukuman fisik dari orang tua atau guru akan menggunakan hukuman fisik sebagai cara untuk menyelesaikan konflik interpersonal yang mereka alami. Hasil penelitian Kitano et al. (2018) juga menunjukkan bahwa remaja yang pernah menerima hukuman fisik dari orang tua secara positif akan mendukung pula penggunaan hukuman fisik sebagai strategi disiplin. Sejalan dengan hasil penelitian tersebut maka penelitian ini juga akan menganalisis hubungan antara penerimaan mitos hukuman fisik dan intensi menggunakan hukuman fisik sebagai strategi disiplin di masa depan pada remaja.

Selain pengalaman menerima hukuman fisik, faktor lain yang dapat memengaruhi penerimaan mitos terkait hukuman fisik pada anak adalah faktor perbedaan jenis kelamin. Mehlhausen-Hassoen (2019) menjelaskan perbedaan jenis kelamin secara langsung maupun tidak langsung memengaruhi sikap orang tua dalam membentuk perilaku anak. 
Orang tua lebih sering menerapkan hukuman fisik pada anak laki-laki dibandingkan pada anak perempuan (Mehlhausen-Hassoen, 2019). Adapun jenis hukuman fisik yang diterapkan berbeda antara ibu dan ayah, ibu cenderung menggunakan hukuman fisik ringan dan ayah cenderung pada bentuk hukuman fisik yang lebih berat (Heilmann, Kelly, \& Watt, 2015).

Selain itu, ringkasan kekerasan dari Kemen PPPA (2020) juga menunjukkan pelaku kekerasan paling banyak adalah laki-laki dibandingkan perempuan. Asumsi ini diperkuat oleh Malherek (2016) yang menyatakan bahwa ayah lebih percaya bahwa hukuman fisik adalah strategi disiplin yang efektif. Berbagai penjelasan tersebut memunculkan asumsi bahwa di masa depan, anak laki-laki yang menerima hukuman fisik akan lebih sering menerapkan strategi disiplin yang sama dengan yang dilakukan orang tuanya dibandingkan anak perempuan karena adanya perbedaan pengalaman yang diterima saat kecil yang dapat memengaruhi penerimaan mereka terhadap penggunaan hukuman fisik.

Penelitian terkait faktor-faktor yang memengaruhi penerimaan mitos hukuman fisik menjadi penting untuk diteliti agar kita dapat memutus rantai penggunaan hukuman fisik karena strategi disiplin tersebut dapat membawa dampak negatif pada perkembangan anak. Meta analisis yang dilakukan Gershoff dan Grogan-Kaylor (2016) memperlihatkan bahwa hukuman fisik yang diberikan oleh orang tua dapat berdampak pada tumbuh kembang anak. Kesehatan mental seperti stres, depresi, menurunnya rasa percaya diri anak, serta meningkatkan perasaan malu, dan ketidakberdayaan merupakan beberapa dampak internalisasi (internalizing) pada anak (Esteves et al., 2018; Gershoff \& GroganKaylor, 2016).

Dampak eksternalisasi (externalizing) juga ditemukan dari penggunaan hukuman fisik pada anak (Gibson \& Fagan, 2018) seperti perilaku antisosial dan nakal, menggunakan dan menjual obat-obatan, mencuri, perilaku agresi, serta menggunakan teknik kekerasan saat memiliki anak di masa depan (Gershoff \& Grogan-Kaylor, 2016; Piché et al., 2017). Selain itu, kekerasan yang dialami oleh anak juga secara signifikan dikaitkan dengan rendahnya internalisasi moral serta penurunan kemampuan kognitif (Font \& Cage, 2017; Wolf \& Suntheimer, 2020). Banyaknya dampak negatif yang dihasilkan dari penerapan hukuman fisik tentu harus diperhatikan oleh orang tua. Hal yang perlu menjadi fokus perhatian adalah adanya kemungkinan anak akan menggunakan teknik yang sama, yaitu penggunaan hukuman fisik sebagai strategi disiplin di masa depan setelah memiliki anak (Gershoff \& Grogan-Kaylor, 2016) yang dapat membuat siklus penggunaan hukuman fisik tidak akan terhenti.

Sampai saat ini sudah banyak penelitian mengenai penggunaan hukuman fisik seperti pengaruh hukuman fisik pada perkembangan anak (Font \& Cage, 2017; Gershoff \& GroganKaylor, 2016; Gibson \& Fagan, 2018; Wolf \& Suntheimer, 2020), alasan orang tua memberikan hukuman fisik pada anak (Wati \& Puspitasari, 2018), atau mengenai perbedaan jenis kelamin anak dan pengaruhnya terhadap kekerasan fisik yang diterima oleh anak (Mehlhausen-Hassoen, 2019). Akan tetapi, penelitian terkait penerimaan akan mitos hukuman fisik terbilang baru karena masih belum banyak diteliti. Sejauh ini, penelitian terkait penerimaan mitos akan hukuman fisik pada individu baru diteliti oleh Kish dan Newcombe (2015) serta Watakakosol et al. (2019) dan belum ditemukan penelitian terkait penerimaan mitos hukuman fisik di Indonesia. Padahal topik ini penting untuk digali lebih lanjut untuk memahami siklus penggunaan hukuman fisik yang masih bertahan sebagai strategi disiplin walaupun strategi ini memiliki dampak negatif pada perkembangan anak. Penelitian ini juga penting dilakukan karena meski saat ini Indonesia sudah memiliki Undang-Undang No. 35 tahun 2014 tentang perlindungan anak dan larangan penggunaan kekerasan pada anak (RI, 2014), namun pada realitanya, data menunjukkan masih banyak anak yang mengalami kekerasan fisik.

Selain itu, dalam rangka mengubah pandangan masyarakat akan norma terkait penggunaan hukuman fisik, penting bagi kita untuk memahami terlebih dahulu faktor pengaruh yang dapat memperkuat penerimaan mitos hukuman fisik tersebut. Penelitian ini merupakan studi awal di Indonesia yang membahas mengenai mitos hukuman fisik dengan tujuan untuk menganalisis pengaruh pengalaman menerima hukuman fisik dan perbedaan jenis kelamin terhadap penerimaan mitos hukuman fisik pada remaja. Selain itu, ada dua hipotesis penelitian yaitu: 1) terdapat pengaruh yang signifikan perbedaan jenis kelamin dan pengalaman menerima hukuman fisik terhadap penerimaan mitos hukuman fisik pada remaja, dan 2) terdapat pengaruh yang signifikan penerimaan mitos hukuman fisik terhadap intensi menggunakan hukuman fisik kepada anak di kemudian hari (Gambar 1). 


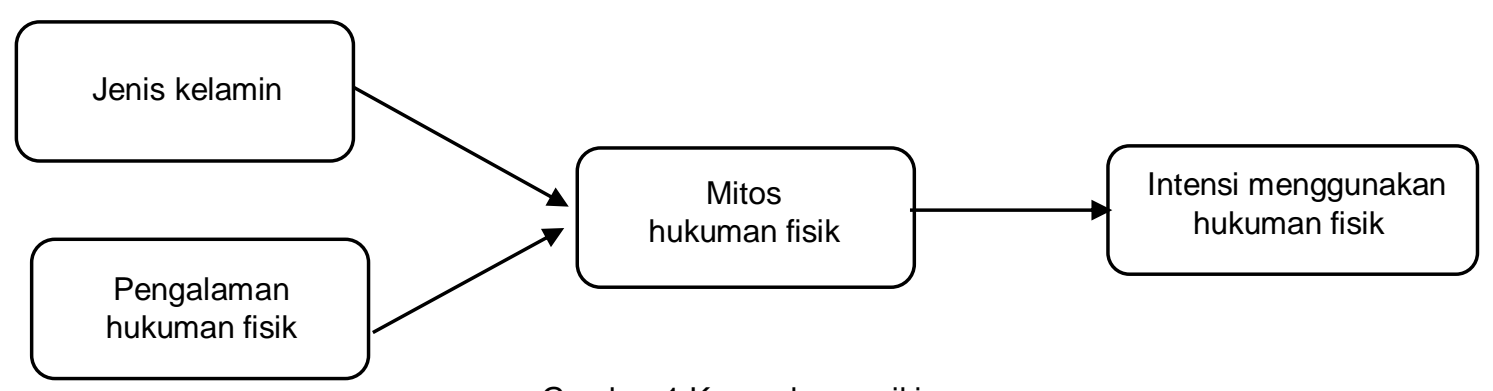

Gambar 1 Kerangka pemikiran

\section{METODE}

Penelitian ini dilakukan dengan menggunakan pendekatan kuantitatif non-eksperimental dengan metode pengumpulan data yang digunakan adalah metode survei. Penelitian ini dilakukan pada bulan Juni sampai Agustus 2020 di wilayah Provinsi Jawa Barat dengan menyebarkan kuesioner secara daring. Pemilihan daerah Jawa Barat sebagai lokasi penelitian didasarkan pada data dari Kemen PPPA (2020) yang menyatakan bahwa Provinsi Jawa Barat termasuk ke dalam lima Provinsi tertinggi yang melakukan kekerasan pada anak. Penyebaran kuesioner online kepada partisipan dilakukan dengan teknik non-probability sampling dengan metode purposive sampling karena partisipan penelitian harus memenuhi beberapa kriteria yang telah ditetapkan oleh peneliti sesuai dengan tujuan penelitian. Sedangkan strategi yang digunakan dalam mengambil sampel penelitian adalah dengan menyebarkan informasi penelitian melalui media sosial seperti Instagram, Twitter, WhatsApp, dan lain-lain. Strategi yang digunakan oleh peneliti dalam menyebarkan kuesioner adalah dengan meminta bantuan kerabat dan teman untuk mengunggah informasi terkait penelitian ini di media sosial yang mereka miliki dengan harapan dapat menjadi pesan berantai sehingga target partisipan dapat terjangkau. Pada penelitian ini, peneliti hanya mengumpulkan partisipan dengan menyebarkan kuesioner online saja karena keterbatasan kondisi akibat pandemi Covid-19 yang sedang berlangsung. Setelah melakukan pengecekan ulang untuk memastikan bahwa seluruh partisipan memenuhi kriteria partisipan yang dibutuhkan, terutama pada kriteria kelompok kelas menengah ke bawah, sebanyak 123 partisipan memenuhi kriteria penelitian dan data dapat dialnjutkan pada proses pengolahan dan analisis data.

Karakteristik partisipan penelitian adalah remaja berusia 13 sampai 17 tahun dan tergolong memiliki status sosial ekonomi menengah ke bawah yang tersebar di Provinsi
Jawa Barat. Pemilihan usia partisipan didasarkan pada data statistik yang dikeluarkan oleh Kemen PPPA (2020) yang menyatakan bahwa anak usia 13-17 tahun merupakan usia yang paling banyak mengalami kekerasan. Selain itu, pemilihan partisipan dengan status sosial ekonomi menengah bawah didasarkan pada beberapa hasil penelitian yang menyatakan bahwa anak yang tinggal dalam kelompok status ekonomi sosial rendah cenderung lebih rentan dan berisiko tinggi mengalami hukuman fisik sebagai strategi disiplin (Choi et al., 2018; Ho, 2019; Vittrup \& Holden, 2010). Selanjutnya, terdapat indikator yang harus terpenuhi oleh partisipan agar dapat dikatakan tergolong memiliki status ekonomi sosial menengah ke bawah. Berdasarkan klasifikasi status sosial ekonomi untuk tahun 2018 yang dibuat oleh Nielsen Company (2017), status sosial ekonomi masyarakat Indonesia dibagi menjadi lima kelompok, yaitu: 1) kelompok A (kelas atas); 2) kelompok B (kelas menengah atas); 3) kelompok $\mathrm{C}$ (kelas menengah); 4) kelompok $D$ (kelas menengah bawah); dan 5) kelompok E (kelas bawah). Penggolongan kelima kelompok ini didasarkan pada sumber air minum, kapasitas daya listrik, jenis bahan bakar yang digunakan untuk memasak, dan jumlah pengeluaran rata-rata untuk keperluan rumah tangga per bulan dan akan diberikan skoring pada setiap jawaban. Total skor yang didapatkan akan menentukan status sosial ekonomi partisipan dengan rincian, golongan kelas atas (skor 20-26), kelas menengah atas (skor 17-19), kelas menengah (skor 11-16), kelas menengah bawah (skor 710), dan kelas menengah (skor 1-6). Pada penelitian ini, peneliti mengambil data partisipan yang masuk ke dalam kelompok $D$ dan kelompok $\mathrm{E}$ sesuai dengan klasifikasi yang dibuat oleh Nielsen Company (2017).

Pengukuran tingkat penerimaan mitos hukuman fisik atau sejauh mana individu percaya dan menerima seperangkat mitos hukuman fisik dilakukan dengan menggunakan kuesioner The Corporal Punishment Myth Scale (CPMS) yang dikembangkan oleh Kish dan Newcombe (2015). CPMS memiliki dua dimensi yaitu 1) 
penting dan efektif dengan contoh butir pernyataan "Hukuman fisik bekerja lebih baik daripada metode disiplin lainnya" dan dimensi selanjutnya 2) tidak berbahaya dengan contoh butir pernyataan "Hukuman fisik yang digunakan untuk mendisiplinkan tidak berbahaya". Alat ukur ini terdiri atas 10 butir penyataan yang diukur menggunakan Skala Likert satu sampai lima yang merepresentasikan 1 (sangat tidak setuju), 2 (tidak setuju), 3 (netral), 4 (setuju), dan 5 (sangat setuju) dengan nilai Cronbach's alpha sebesar 0,84. Pada penelitian ini, alat ukur CPMS telah diadaptasi kedalam Bahasa Indonesia yang terdiri atas 10 butir pernyataan yang juga diukur menggunakan Skala Likert satu sampai lima yang merepresentasikan 1 (sangat tidak setuju), 2 (tidak setuju), 3 (netral), 4 (setuju), dan 5 (sangat setuju) dengan nilai Cronbach's alpha sebesar 0,918. Skoring dilakukan dengan menjumlahkan seluruh skor yang didapat dari masing-masing butir. Semakin tinggi total skor menunjukkan semakin tingginya penerimaan mitos terkait hukuman fisik dan sebaliknya.

Hukuman menggunakan kekerasan fisik adalah bentuk strategi disiplin yang digunakan oleh orang tua dan diukur menggunakan kuesioner The Parent-child Conflict Tactic Scale (CTSPC) yang dikembangkan oleh Straus et al. (1998). Alat ukur ini terdiri tiga subskala (nonviolent, psychological aggression, dan physical assault) dengan total 22 butir. Pada penelitian ini pengukuran hanya menggunakan subskala physical assault yang terdiri atas 13 butir yang mengukur strategi disiplin mulai dari bentuk hukuman fisik (corporal punishment) hingga kekerasan fisik (physical abuse). Penggunaan subskala physical assault dilakukan sesuai kebutuhan penelitian dan berdasarkan beberapa penelitian yang sudah dilakukan, subskala physical assault dapat digunakan secara terpisah (Bartlett \& Easterbrooks, 2012; Zhai, Waldfogel, \& Brooks-Gunn, 2013). CTSPC diukur menggunakan menggunakan 7 poin skala pengukuran mulai dari 1 (sekali dalam seminggu terakhir), 2 (dua kali dalam seminggu terakhir), 3 (3-5 kali dalam seminggu terakhir), 4 (6-10 kali dalam seminggu terakhir), 5 (11-20 kali dalam seminggu terakhir), 6 (lebih dari 20 kali dalam seminggu terakhir), dan 0 (tidak pernah terjadi dalam seminggu terakhir). Nilai Cronbach's alpha pada subskala physical assault adalah 0,55. Meski nilai Cronbach's alpha terbilang rendah, akan tetapi alat ukur ini masih dapat digunakan karena berdasarkan uji alat ukur yang dilakukan oleh Straus et al. (1998) subskala physical assault memiliki butirbutir pernyataan yang mengukur bentuk hukuman fisik yang jarang dilakukan di kehidupan sehari-hari seperti mengancam dengan pisau atau pistol. Pada Penelitian ini, CTSPC telah diadaptasi ke Bahasa Indonesia yang terdiri atas 22 butir pernyataan dan diukur menggunakan menggunakan 5 poin skala pengukuran mulai dari tidak pernah (0 kali), jarang (1-5 kali), kadang (6-10 kali), sering (1120 kali), sangat sering (>20 kali) dengan nilai Cronbach's alpha sebesar 0,902. Skala pengukuran yang digunakan dalam penelitian ini menggunakan skala pengukuran alternatif yang diberikan oleh Straus et al. (1998) dengan sedikit modifikasi menambahkan jumlah frekuensi yang ada pada skala pengukuran asli untuk mempermudah partisipan dalam pengisian kuesioner. Skoring dilakukan dengan menggunakan nilai median dari masing-masing skala, tidak pernah (skor 0), jarang (skor 3), kadang (skor 8), sering (skor 15), dan sangat sering (skor 25). Pada penelitian ini, partisipan diminta untuk mengingat kembali apa strategi disiplin yang digunakan oleh orang tuanya selama 6 bulan terakhir. Total skor tinggi menunjukkan strategi disiplin yang abusif dan sebaliknya.

Intensi penggunaan hukuman fisik pada remaja diukur dengan menggunakan corporal punishment uses intensions yang dikembangkan oleh Kish dan Newcombe (2015). Alat ukur ini merupakan sebuah skenario kenakalan anak yang digunakan untuk mengetahui intensi partisipan dalam menggunakan hukuman fisik. Pada penelitian ini, skenario telah diadaptasi dalam Bahasa Indonesia dan terdiri atas empat cerita yang menceritakan hubungan antara ibu dan anak. Partisipan diminta untuk memosisikan diri sebagai orang tua dan kemudian merespons keempat cerita kenakalan anak untuk melihat kemungkinan partisipan akan menggunakan beberapa bentuk hukuman fisik (memukul, menampar, dan lain-lain), mengabaikan perilaku anak, memberlakukan time out pada anak, menjelaskan pada anak bahwa perilakunya salah, atau menggunakan teknikteknik disiplin lainnya. Pada empat cerita yang disajikan, skenario hukuman fisik dibedakan berdasarkan: usia anak (4 dan 9 tahun), jenis kelamin (perempuan dan laki-laki), lokasi perilaku kenakalan ditunjukkan (rumah atau tempat umum), serta jenis dari kenakalan anak (verbal vs fisik). Partisipan diminta untuk memilih salah satu skenario secara acak berdasarkan jenis kelamin dan usia anak (Aldi 4 tahun/Aldi 9 tahun/Luna 4tahun/Luna 9 tahun), Respons dari masing-masing skenario akan diberi skor 0 untuk teknik disiplin yang tidak menggunakan hukuman fisik dan skor 1 untuk 
teknik disiplin dengan hukuman fisik. Jawaban yang diperoleh dijumlahkan dengan total skor berada pada rentang 0 sampai 4. Semakin tinggi total skor maka mencerminkan niat yang lebih besar untuk menggunakan hukuman fisik di masa depan. Berikut merupakan dua dari empat skenario yang digunakan pada penelitian, Skenario 1) Pada suatu sore, Aldi/Luna sedang menonton acara TV favoritnya, di saat ibunya memasak untuk makan malam. Selama menonton dengan serius dan fokus, ibu memintanya untuk mematikan TV karena sudah masuk waktu makan malam. Namun, Aldi tetap tertarik untuk menonton program TV favoritnya, dan berteriak, "TIDAK!" lalu memukul ibunya. Skenario 2) Pada suatu sore, Aldi/Luna sedang makan malam di restoran dengan kedua orang tuanya. Saat tengah menikmati makanannya, ibu memintanya secara baik-baik untuk menghabiskan seluruh makanan yang ada di piringnya, termasuk dengan sayurannya. Namun, Aldi menolak menuruti ibu dan mulai melemparkan makanan-makanannya ke lantai, sambil marah dan memaksa ibu mengerti kalau ia tidak menyukai dan tidak mau memakan tomat dan wortel.

Analisis data dilakukan dengan menggunakan software IBM SPSS Statistics 24. Pengolahan data menggunakan teknik analisis statistik deskriptif untuk memperoleh gambaran karakteristik demografis partisipan yang meliputi jenis kelamin, usia, pendidikan, domisili, dan status sosial ekonomi. Kemudian Uji paired sample T-test dilakukan untuk mengetahui perbedaan pada dimensi penerimaan mitos hukuman fisik dan Uji Wilcoxon untuk mengetahui perbedaan pengalaman hukuman fisik selama enam bulan terakhir berdasarkan kategori pada partisipan. Terakhir uji analisis jalur dilakukan untuk mengetahui 1) pengaruh jenis kelamin dan pengalaman hukuman fisik terhadap penerimaan mitos hukuman fisik serta 2) pengaruh penerimaan mitos hukuman fisik terhadap intensi penggunaan hukuman fisik pada remaja.

\section{HASIL}

\section{Karakteristik Demografis Remaja}

Hasil penelitian memperlihatkan, mayoritas partisipan berjenis kelamin perempuan (74\%) dan sisanya berjenis kelamin laki-laki (26\%). Selanjutnya berdasarkan usia, rata-rata usia partisipan adalah 15,68 tahun dengan rincian sepertiga partisipan termasuk dalam kategori remaja madya berusia 16-17 tahun dan sedang menempuh Pendidikan SMA/SMK, dan sisanya tergolong dalam kategori remaja awal yang berusia 13-15 tahun dan sedang menempuh Pendidikan SMP. Pada penelitian ini, partisipan penelitian berasal dari beberapa kota besar di Jawa Barat seperti Sumedang, Tasikmalaya dan Bandung. Terakhir berdasarkan status ekonomi sosial, lebih dari setengah jumlah partisipan tergolong dalam kelas menengah bawah $(61 \%)$ dan sisanya tergolong dalam kelas bawah (39\%). Hal ini mengindikasikan bahwa target partisipan penelitian yang didapatkan tidak cukup merata dan dapat berdampak pada hasil analisis (Gambar 2).
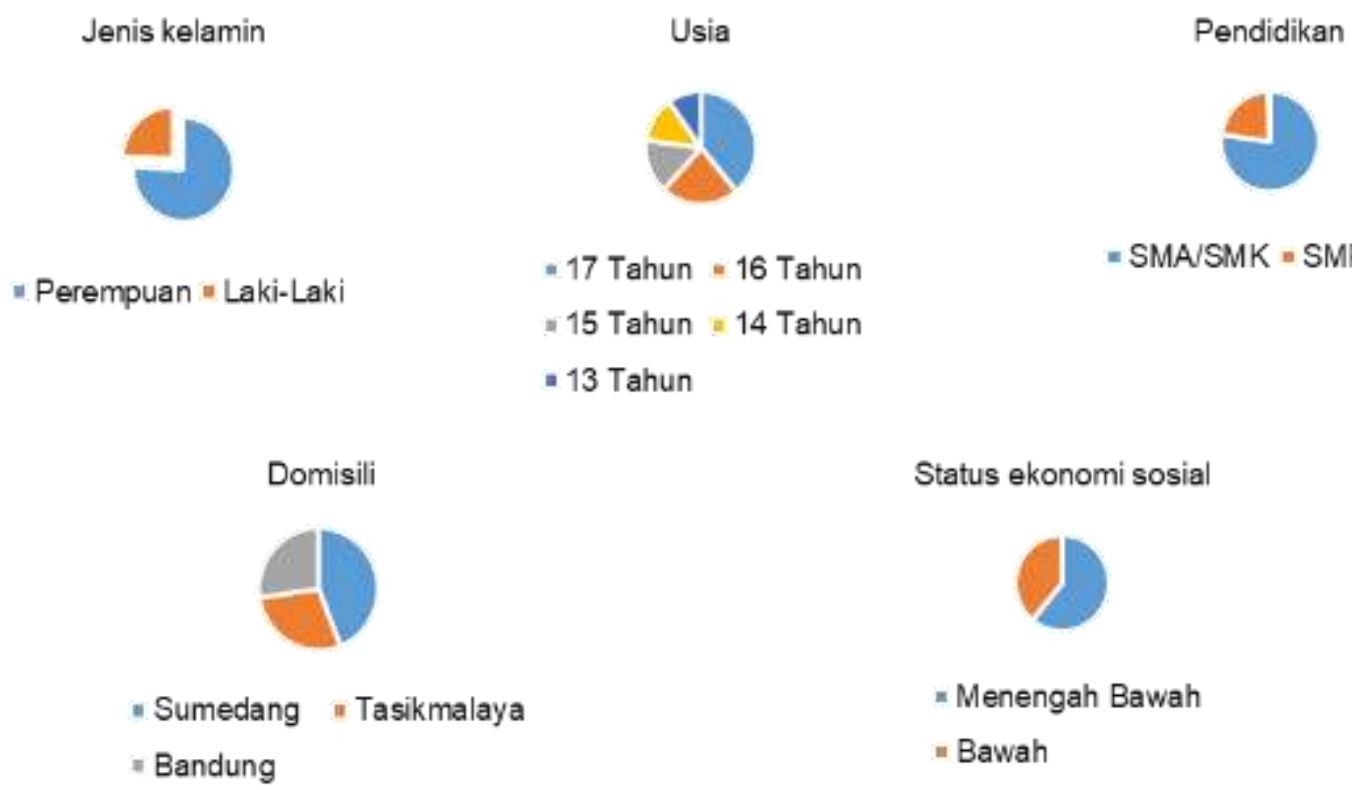

$$
\begin{aligned}
& ₫ 17 \text { Tahun }=16 \text { Tahun } \\
& ₫ 15 \text { Tahun } ₫ 14 \text { Tahun } \\
& ₫ 13 \text { Tahun }
\end{aligned}
$$

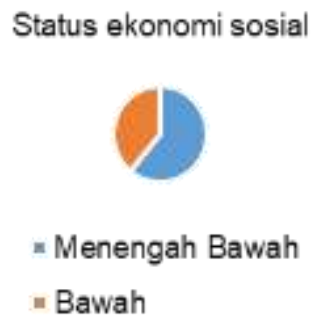

Gambar 2 Sebaran responden berdasarkan karakteristik demografis 
Tabel 1 Rata-rata, standar deviasi, t hitung, skor minimum, skor maksimum, dan signifikansi mitos hukuman fisik

\begin{tabular}{lrrrr}
\hline \multicolumn{1}{c}{ Variabel } & $\mathrm{M} \pm \mathrm{SD}$ & $\begin{array}{c}\mathrm{t}- \\
\text { hitun } \\
\mathrm{g}\end{array}$ & $\begin{array}{c}\text { Min - } \\
\text { Maks }\end{array}$ & Sig. \\
\hline $\begin{array}{l}\text { Mitos } \\
\text { hukuman fisik } \\
\text { (skor 0 - 50) }\end{array}$ & $\begin{array}{r}28,19 \pm \\
9,198\end{array}$ & & $10-50$ & - \\
$\begin{array}{l}\text { Dimensi } \\
\text { penting \& }\end{array}$ & $14,72 \pm$ & 3,32 & $5-25$ & 0,000 \\
efektif & 4,936 & 8 & & \\
$\begin{array}{l}\text { Dimensi tidak } \\
\text { berbahaya }\end{array}$ & $13,46 \pm$ & 3,32 & $5-25$ & 0,000 \\
\hline
\end{tabular}

Keterangan: *Signifikan pada LoS 0,05 (2-tailed); M=ratarata; $S D=$ standar deviasi; $M i n=$ minimum; Maks=maksimum

\section{Mitos Hukuman Fisik}

Mitos hukuman fisik atau kepercayaan terkait penggunaan hukuman fisik sebagai strategi disiplin dilihat dari dua dimensi, yaitu: 1) penting dan efektif serta 2) tidak bahaya. Hasil analisis deskriptif menunjukkan bahwa secara keseluruhan, skor penerimaan mitos hukuman fisik bervariatif dengan skor minimum yang didapatkan adalah 10 dan skor maksimum berjumlah $50 \quad(M=28,19 ; \quad S D=9,198)$ yang artinya remaja yang menjadi partisipan penelitian memiliki pandangan yang berbeda terkait penerimaan mitos hukuman fisik. Hasil ini menunjukkan bahwa remaja menunjukkan penerimaan mitos yang lebih tinggi mengenai anggapan bahwa hukuman fisik merupakan sesuatu yang penting dan efektif dibandingkan anggapan bahwa hukuman fisik tidak berbahaya.

\section{Dimensi Penting dan Efektif dari Mitos Hukuman Fisik}

Dimensi ini menggambarkan penerimaan individu bahwa hukuman fisik dianggap penting dan efektif untuk digunakan. Berdasarkan uji paired sample T-test didapatkan data bahwa terdapat perbedaan yang signifikan $(p<0,005)$ pada kedua dimensi dalam mitos hukuman fisik. Berdasarkan nilai rata-rata yang lebih tinggi $(M=14,72)$ diketahui bahwa partisipan penelitian menganggap bahwa hukuman fisik bekerja lebih baik daripada metode disiplin lainnya, hukuman fisik membantu anak untuk tidak menjadi manja dan liar, hukuman fisik mengajarkan anak cara menghormati orang lain, hukuman fisik merupakan satu-satunya bentuk disiplin yang dimengerti oleh anak, dan hukuman fisik efektif untuk digunakan saat anak berkelakuan buruk.

\section{Dimensi Tidak Berbahaya dari Mitos Hukuman Fisik}

Dimensi ini menggambarkan penerimaan individu bahwa hukuman fisik dianggap tidak berbahaya untuk diterapkan kepada anak. Sama seperti hasil uji pada dimensi sebelumnya, hasil uji paired sample T-test menunjukkan hasil bahwa terdapat perbedaan yang signifikan $(p<0,005)$ pada kedua dimensi dalam mitos hukuman fisik. Meski nilai rata-rata yang didapatkan lebih rendah $(M=13,46)$, berdasarkan dimensi ini diketahui bahwa remaja yang menjadi partisipan menganggap bahwa hukuman fisik sebagai strategi disiplin tidak berbahaya, tidak menyebabkan kerusakan pada anak, realistis dan boleh untuk diterapkan oleh orang tua, serta dapat diterapkan baik pada laki-laki maupun perempuan (Tabel 1).

\section{Pengalaman Menerima Hukuman Fisik Sebagai Bentuk Strategi Disiplin}

Hukuman fisik sebagai strategi disiplin merupakan satu dari tiga bentuk strategi disiplin yang biasa diterapkan oleh orang tua. Pada penelitian ini, bentuk hukuman fisik yang pernah diterima oleh partisipan dilihat dari dua kategori, yaitu kategori ringan dan berat. Berdasarkan hasil analisis deskriptif didapatkan data bahwa secara keseluruhan skor minimum yang didapatkan adalah 0 atau tidak pernah sama sekali menerima hukuman fisik dari orang tua dan skor maksimum adalah 80 yang artinya partisipan penelitian tergolong rendah mengalami hukuman fisik sebagai bentuk strategi disiplin orang tua selama enam bulan terakhir ( $M=9,7 ; S D=13,794)$ (Tabel 2).

\section{Kategori Ringan dalam Menerima Hukuman Fisik}

Kategori ini menggambarkan bentuk-bentuk hukuman fisik yang tergolong ringan bagi anak. Berdasarkan hasil uji Wilcoxon yang dilakukan untuk melihat perbedaan pengalaman hukuman fisik selama 6 bulan terakhir pada remaja dapat diketahui bahwa terdapat perbedaan yang signifikan $(p<0,05)$ antara jenis pengalaman hukuman fisik yang diterima oleh remaja.

Tabel 2 Rata-rata, standar deviasi, skor minimum, skor maksimum, dan signifikansi pengalaman hukuman fisik

\begin{tabular}{lccc}
\hline \multicolumn{1}{c}{ Variabel } & $\mathrm{M} \pm \mathrm{SD}$ & $\begin{array}{c}\text { Min - } \\
\text { Maks }\end{array}$ & Sig. \\
\hline $\begin{array}{l}\text { Pengalaman } \\
\text { hukuman fisik } \\
\text { (skor 0-325) }\end{array}$ & $9,7 \pm 13,794$ & $0-80$ & - \\
Kategori ringan & $7,54 \pm 9,148$ & $0-40$ & $0,000^{*}$ \\
Kategori berat & $2,15 \pm 6,203$ & $0-40$ & $0,000^{*}$ \\
\hline
\end{tabular}

Keterangan: *Signifikan pada LoS 0,05 (2-tailed); M=ratarata; $\mathrm{SD}=$ standar deviasi; $\mathrm{Min}=$ minimum; Maks=maksimum 
Tabel 3 Hasil uji analisis jalur model 1

\begin{tabular}{|c|c|c|c|}
\hline \multirow[t]{2}{*}{ Variabel bebas } & \multicolumn{2}{|c|}{$\begin{array}{c}\text { Penerimaan mitos } \\
\text { penggunaan } \\
\text { hukuman fisik }\end{array}$} & \multirow[t]{2}{*}{ Sig. } \\
\hline & $B$ & $\beta$ & \\
\hline Konstanta & 32,644 & & 0,000 \\
\hline $\begin{array}{l}\text { Jenis kelamin } \\
\text { anak } \quad(0=1 ; \\
1=p)\end{array}$ & $-5,306$ & $-0,262$ & $0,004^{\star *}$ \\
\hline $\begin{array}{l}\text { Pengalaman } \\
\text { hukuman fisik }\end{array}$ & $-0,050$ & $-0,076$ & 0,405 \\
\hline $\mathrm{F}$ & & 4,221 & \\
\hline Sig & & $0,017^{* *}$ & \\
\hline$R^{2}$ & & 0,066 & \\
\hline Adj $R^{2}$ & & 0,050 & \\
\hline
\end{tabular}

Keterangan: **signifikan pada $p<0,05 ; B=k o e f i s i e n$ regresi belum terstandar; $\beta=$ koefisien regresi sudah terstandar

Berdasarkan nilai rata-rata yang lebih tinggi diketahui bahwa bentuk-bentuk hukuman fisik yang biasa diterima oleh remaja tergolong ringan seperti mengguncang tubuh, memukul bokong, lengan, atau bagian tangan.

\section{Kategori Berat dalam Menerima Hukuman Fisik}

Kategori ini menggambarkan bentuk-bentuk hukuman fisik yang tergolong berat bagi anak. Sama seperti analisis sebelumnya, berdasarkan hasil uji Wilcoxon yang dilakukan untuk melihat perbedaan pengalaman hukuman fisik selama enam bulan terakhir pada remaja dapat diketahui, terdapat perbedaan yang signifikan $(p<0,05)$ antara jenis pengalaman hukuman fisik yang diterima oleh remaja. Berdasarkan nilai rata-rata yang lebih rendah diketahui bahwa bentuk hukuman fisik yang tergolong berat seperti menendang dengan keras, mengancam dengan pisau, dan memegang area leher jarang diterima oleh remaja.

\section{Pengaruh Jenis Kelamin Anak dan Pengalaman Hukuman Fisik terhadap Penerimaan Mitos Hukuman Fisik pada Remaja}

Hasil uji analisis jalur model 1 memperlihatkan bahwa model penelitian memiliki nilai koefisien determinasi (Adjusted $\mathrm{R}^{2}$ ) sebesar 0,050 secara signifikan. Hal tersebut menunjukkan bahwa sebesar 5 persen penerimaan mitos hukuman fisik pada remaja dipengaruhi oleh variabel di dalam penelitian secara simultan, sedangkan sisanya 95 persen dipengaruhi oleh variabel lain di luar penelitian (Tabel 3).

Hasil menunjukkan bahwa perbedaan jenis kelamin berperan kecil $(B=-5,306)$ terhadap penerimaan mitos hukuman fisik dengan rincian remaja laki-laki memiliki penerimaan mitos hukuman fisik yang lebih tinggi dibandingkan remaja perempuan. Sedangkan pengalaman hukuman fisik yang diterima oleh remaja tidak berpengaruh terhadap penerimaan mitos hukuman fisik $(p>0,05)$.

Selanjutnya hasil uji analisis jalur model 2 menunjukkan bahwa mitos hukuman fisik berpengaruh positif signifikan terhadap intensi menggunakan hukuman fisik pada remaja. Hasil menunjukkan bahwa setiap kenaikan satu satuan nilai variabel mitos hukuman fisik akan meningkatkan 0,205 satuan intensi menggunakan hukuman fisik. Hasil uji juga menunjukkan bahwa perbedaan jenis kelamin dan pengalaman hukuman fisik tidak memiliki pengaruh langsung terhadap intensi menggunakan hukuman fisik pada remaja $(p>0,05)$, hal ini menunjukkan bahwa hubungan antara jenis kelamin dan pengalaman hukuman fisik dengan intensi menggunakan hukuman fisik memang harus dimediasi oleh mitos hukuman fisik (Gambar 3).



Keterangan: $\epsilon=$ Galat, ${ }^{*}$ signifikan pada $p<0,05$ 


\section{PEMBAHASAN}

Hasil penelitian menunjukkan bahwa penerimaan mitos hukuman fisik dipengaruhi secara signifikan oleh perbedaan jenis kelamin. Temuan ini sejalan dengan penelitian yang dilakukan oleh Sherbert Research (2007) yang menyatakan bahwa anak laki-laki memiliki pandangan yang berbeda dengan anak perempuan terkait penggunaan hukuman fisik sebagai strategi disiplin. Hal ini dapat diakibatkan karena penggunaan hukuman fisik sebagai strategi disiplin memang lebih banyak dilakukan oleh orang tua kepada anak lakilakinya dibanding anak perempuannya sehingga penerimaan anak laki-laki terhadap penggunaan hukuman fisik lebih kuat dibandingkan anak perempuan. Selain itu, adanya proses pembelajaran melalui observasi juga dapat memengaruhi perbedaan penerimaan mitos hukuman fisik pada remaja laki-laki dan perempuan.

Teori Kognitif Sosial (Bandura, 1986) yang menyoroti proses pembelajaran observasional melalui pengalaman langsung dapat menjelaskan perbedaan penerimaan mitos hukuman fisik pada remaja laki-laki dan perempuan. Sebagaimana diketahui, proses modelling melalui pembelajaran secara observasi dapat dilakukan oleh remaja kepada figur otoritas seperti orang tua. Dalam teori ini dijelaskan bahwa anak akan cenderung meniru perilaku yang ditunjukkan oleh figur otoritas karena menganggap bahwa perilaku tersebut tepat untuk dilakukan. Sejalan dengan teori Kognitif Sosial, Kuhl, Warner, dan Wilczak (2012) juga menjelaskan bahwa masa remaja merupakan masa berkembangnya kemampuan kognitif dan psikologis yang dapat berperan dalam pengambilan keputusan yang dilakukan dan perkembangan kedua aspek ini dapat membentuk kehidupan anak di masa depan. Jika dikaitkan dengan hasil penelitian tersebut, maka pengalaman hukuman fisik yang diterima oleh individu saat remaja dapat memengaruhi perkembangan kognitif serta cara mereka memandang pengalaman tersebut dan pada akhirnya memengaruhi pola pikir serta penerimaan mereka bahwa hukuman fisik tepat digunakan di kemudian hari sebagai strategi disiplin.

Hal lain yang dapat memengaruhi perbedaan penerimaan mitos hukuman fisik pada remaja laki-laki dan perempuan adalah karena adanya perbedaan sudut pandang terkait peran gender. Hasil penelitian Sherbert Research (2007) pada anak dan remaja menunjukkan bahwa anak laki-laki memiliki pandangan bahwa mereka sering diberi label sebagai pembuat masalah karena mereka kurang mampu mengungkapkan dan mengomunikasikan pandangan dan kebutuhannya dengan katakata sehingga mereka menggunakan tindakan fisik untuk berekspresi. Mereka juga percaya bahwa memukul anak laki-laki lebih diterima secara sosial daripada memukul anak perempuan dengan alasan laki-laki itu lebih kuat dan mampu menerimanya, memukul adalah jenis hukuman yang lebih bisa diterima anak laki-laki, dan hukuman fisik dapat mempersiapkan mereka untuk menjadi seorang individu. Berbeda dengan anak laki-laki, anak perempuan dianggap lebih cepat dewasa karena bisa lebih mengekspresikan dirinya secara kompeten dengan kata-kata dibandingkan menggunakan tindakan fisik. Jika dikaitkan dengan hasil penelitian Sherbert Research (2007), maka adanya perbedaan sudut pandang tersebut bisa menjadi salah satu hal yang memengaruhi penerimaan hukuman fisik pada remaja. Penelitian lanjutan perlu dilakukan untuk mencari tahu lebih dalam mengenai faktor-faktor yang dapat memengaruhi perbedaan remaja laki-laki dan perempuan dalam penerimaan mitos hukuman fisik.

Selanjutnya, hasil uji analisis jalur juga menunjukkan bahwa penerimaan mitos hukuman fisik tidak dipengaruhi secara signifikan oleh pengalaman menerima hukuman fisik. Hal ini cukup mengejutkan namun hasil ini sejalan dengan hasil penelitian yang dilakukan oleh Watakakosol et al. (2019) di Thailand yang menyatakan bahwa pengalaman hukuman fisik yang diterima anak pada usia 10 tahun tidak memengaruhi penerimaan mitos hukuman fisik. Dalam penelitiannya, Watakakosol et al. (2019) menjelaskan bahwa hal ini dapat terjadi karena bentuk hukuman fisik yang diterima oleh remaja masih dianggap wajar dan tidak terlalu membahayakan diri mereka sehingga membuat pengalaman menerima hukuman fisik tidak berpengaruh terhadap pembentukan mitos hukuman fisik.

Hasil penelitian ini bertentangan dengan beberapa hasil penelitian sebelumnya yang menyatakan bahwa pengalaman menerima hukuman fisik memengaruhi penerimaan penggunaan hukuman fisik. Seperti contoh, hasil penelitian Bell dan Romano (2012) yang menyatakan bahwa semakin tinggi pengalaman hukuman fisik saat kecil secara signifikan memprediksi sikap yang lebih positif terhadap tamparan. Selain itu, hasil penelitian Simons dan Wurtele (2010) juga menyatakan bahwa anak yang tinggal dengan orang tua yang 
menerapkan hukuman fisik sebagai strategi disiplin akan menerima hukuman fisik sebagai metode yang tepat dalam menyelesaikan konflik interpersonal. Melihat kedua hasil penelitian tersebut, seharusnya pengalaman menerima hukuman fisik dapat berpengaruh terhadap pembentukan mitos hukuman fisik pada remaja. Akan tetapi jika ditelaah dari hasil penelitian yang menunjukkan bahwa sebagian besar pengalaman hukuman fisik yang remaja terima berada dalam kategori ringan memunculkan asumsi bahwa bisa saja bentuk hukuman fisik yang ringan seperti memukul area bokong, lengan atau tangan, dan mencubit memang tidak berpengaruh terhadap pembentukan mitos hukuman fisik pada remaja.

Asumsi ini sejalan dengan hasil penelitian oleh Vittrup dan Holden (2010) yang menyatakan bahwa anak yang terpapar hukuman fisik dengan frekuensi sedang akan lebih menerima bahwa hukuman fisik tepat untuk dilakukan dibandingkan dengan anak yang terpapar hukuman fisik dengan frekuensi rendah dan tinggi. Hasil penelitian Witt et al. (2017) juga menunjukkan bahwa individu yang mengalami bentuk kekerasan fisik dengan kategori berat berasosiasi dengan tingginya dukungan dan penerimaan akan penggunaan hukuman fisik. Jika dikaitkan dengan hasil temuan yang menyatakan bahwa partisipan cenderung berada dalam kategori rendah menerima hukuman fisik dalam 6 bulan terakhir, maka hasil penelitian ini menjadi masuk akal karena remaja dalam penelitian ini tergolong jarang dan bentuk hukuman fisik yang diterima tegolong dalam kategori ringan sehingga membuat mereka menganggap hukuman fisik bukanlah sesuatu yang bersifat normatif dan membentuk anggapan bahwa hukuman fisik bukan metode strategi disiplin yang baik untuk dilakukan. Penelitian lanjutan perlu dilakukan untuk mencari tahu faktor lain yang membuat pengalaman hukuman fisik tidak memengaruhi penerimaan mitos hukuman fisik. Dengan berbagai penjelasan tersebut maka diketahui bahwa hipotesis 1 diterima secara parsial.

Terakhir, mitos hukuman fisik berpengaruh terhadap intensi menggunakan hukuman fisik (berdasarkan tanggapan partisipan pada skenario yang diberikan). Hasil penelitian ini mendukung hasil penelitian Kish dan Newcombe (2015) serta Watakakosol et al. (2019) yang juga menunjukkan bahwa partisipan yang memiliki penerimaan mitos hukuman fisik yang lebih tinggi akan menunjukkan intensi menggunakan hukuman fisik sebagai strategi disiplin anak. Hasil ini diperkuat oleh temuan Simons dan Wurtele
(2010) yang menyatakan bahwa penerimaan orang tua terhadap penggunaan hukuman fisik secara signifikan berhubungan positif dengan frekuensi penggunaan hukuman fisik pada anak mereka. Hasil penelitian lain juga menunjukkan bahwa sikap partisipan terhadap penggunaan hukuman fisik secara signifikan berhubungan dengan dukungan mereka menggunakan hukuman fisik pada anak, yang artinya semakin positif pandangan partisipan terhadap penggunaan hukuman fisik maka akan semakin tinggi intensi penggunaan hukuman fisik pada anak (Walker, Streans, \& McKinney, 2018). Hasil penelitian ini dapat menjadi pertimbangan bahwa penting untuk memahami mitos hukuman fisik dan pengaruhnya terhadap penggunaan hukuman fisik di masa depan karena ketika individu memiliki penerimaan mitos hukuman fisik yang tinggi maka rantai penggunaan hukuman fisik sebagai strategi disiplin tidak akan terputus dan akan terus berlanjut ke generasi selanjutnya. Dengan demikian maka hipotesis dua diterima.

Hasil studi awal terkait penerimaan mitos hukuman fisik di Indonesia menunjukkan bahwa pengalaman mendapatkan hukuman fisik dari orang tua tidak memengaruhi penerimaan mitos hukuman fisik, namun perbedaan jenis kelamin secara signifikan memengaruhi penerimaan mitos hukuman fisik pada remaja. Hasil menunjukkan bahwa remaja laki-laki memiliki penerimaan yang lebih tinggi pada mitos hukuman fisik dibandingkan remaja perempuan. Selain itu, penerimaan mitos hukuman fisik berpengaruh terhadap intensi menggunakan hukuman fisik.

Hasil penelitian ini dapat membantu masyarakat dan para praktisi dalam memahami berbagai faktor seperti pengalaman hukuman fisik dan perbedaan jenis kelamin yang dapat memengaruhi penerimaan mitos hukuman fisik pada remaja serta dampak dari tingginya penerimaan mitos hukuman fisik terhadap intensi menggunakan hukuman fisik di masa depan. Hasil penelitian ini diharapkan dapat membantu pembaca memahami siklus penggunaan hukuman fisik yang tetap bertahan sebagai strategi disiplin meskipun Negara Indonesia telah berkomitmen untuk menghentikan penggunaan hukuman fisik sebagai strategi disiplin pada anak. Hasil penelitian ini juga dapat membantu dalam meningkatkan pemahaman dan kesadaran masyarakat mengenai hukuman fisik, dampak dari penggunaan hukuman fisik pada perkembangan anak, dan seberapa tinggi intensi anak menggunakan hukuman fisik di masa depan. 


\section{SIMPULAN DAN SARAN}

Penelitian ini memiliki beberapa keterbatasan yang dapat dikembangkan pada penelitian selanjutnya. Pertama, jumlah partisipan terbilang sedikit. Hal ini terjadi karena adanya keterbatasan dalam pengambilan data akibat situasi pandemi Covid-19 yang sedang berlangsung. Penelitian ini hanya menggunakan sosial media dalam menjaring partisipan, sedangkan kriteria partisipan yang ditargetkan adalah partisipan dengan golongan kelas menengah ke bawah. Hal ini perlu dijadikan pertimbangan dalam pengambilan data pada penelitian selanjutnya untuk menyebarkan kuesioner secara langsung dengan mendatangi permukiman atau sekolah yang padat dengan masyarakat kelas menengah bawah agar jumlah partisipan lebih banyak dan lebih merepresentasikan contoh penelitian. Limitasi kedua adalah pernyataan yang terlampir dalam alat ukur CTSPC cukup sensitif sehingga memunculkan kemungkinan partisipan tidak menjawab dengan jujur atau melakukan faking good yang dapat memengaruhi hasil penelitian. Oleh sebab itu, perlu dilakukan adanya kontrol lebih misalnya menggunakan alat ukur tambahan yang dapat mengontrol kemungkinan adanya social desirability. Limitasi terakhir adalah perlunya data mengenai pendidikan terakhir orang tua karena hal ini mungkin dapat memengaruhi orang tua dalam menggunakan hukuman fisik pada anak dan membentuk penerimaan anak terhadap mitos hukuman fisik.

Saran yang dapat diberikan baik pada institusi pemerintahan maupun lembaga lain yang berkaitan dengan keluarga dan anak adalah menyusun kebijakan yang lebih kuat untuk melindungi anak dari penggunaan hukuman fisik sebagai strategi disiplin. Meski sudah ada pasal-pasal yang mengatur tentang perlindungan anak, tetapi pada kenyataannya masih banyak kasus kekerasan yang dialami oleh anak sehingga penting bagi institusi dan lembaga terkait untuk mencari cara agar dapat memutus rantai kekerasan pada anak. Praktisi juga dapat membuat rancangan program atau modul terkait parenting dengan menggunakan data hasil penelitian ini. Terakhir, penelitian lanjutan juga perlu dilakukan untuk lebih mengeksplorasi faktor-faktor lain yang mungkin berpengaruh dalam penerimaan mitos hukuman fisik sehingga secara perlahan kita dapat memutus siklus penggunaan hukuman fisik sebagai strategi disiplin pada anak.

\section{DAFTAR PUSTAKA}

Bandura, A. (1986). Social foundations of thought and action: A social cognitive theory. Englewood Cliffs, NJ: Prentice Hall.

Bartlett, J. D., \& Easterbrooks, M. A. (2012). Links between physical abuse in childhood and child neglect among adolescent mothers. Children and Youth Services Review, 34(11), 2164-2169. doi:10.1016/j.childyouth.2012.07.011.

Bell, T., \& Romano, E. (2012). Opinions about child corporal punishment and influencing factors. Journal of Interpersonal Violence, 27(11), 2208-2229. doi:10.1177/0886260511432154.

Bornstein, M. H. (2013). Parenting and child mental health: A cross-cultural perspective. World Psychiatry, 12(3), 258-265. doi:10.1002/wps.20071.

Breen, A., Daniels, K., \& Tomlinson, M. (2015). Children's experiences of corporal punishment: A qualitative study in an urban township of South Africa. Child Abuse Negl., 48, 131-139. doi:10.1016/j.chiabu.2015.04.022.

Chiocca, E. M. (2017). American parents' attitudes and beliefs about corporal punishment: An integrative literature review. Journal of Pediatric Health Care, $31(3), \quad 372-383 . \quad$ doi:10.1016/j.pedhc .2017.01.002.

Choi, S., Yoo, J., Park, J., Lee, H., Tran, H. T. G., Lee, J., \& Oh, J. (2018). Manifestations of socioeconomic status and its association with physical child punishment results from the multi-indicators cluster survey in Viet Nam 2006-2014. Child Abuse Negl, 85, 1-8. doi:10.1016/j.chiabu.2018.08.022.

Esteves, K., Gray, S. A. O., Theall, K. P., \& Drury, S. S. (2018). Impact of physical abuse on internalizing behavior across generations. HHS Public Access, 26(10), 2753-2761. doi:10.1007/s10826-0170780-y.Impact.

Font, S. A., \& Cage, J. (2017). Dimensions of physical punishment and their associations with children's cognitive performance and school adjustment. Child Abuse and Neglect, 75, 29-40. doi:10.1016/j.chiabu.2017.06.008.

Fréchette, S., \& Romano, E. (2017). How do parents label their physical disciplinary practices? A focus on the definition of corporal punishment. Child Abuse and Neglect, 71, 92-103. doi:10.1016/j.chiabu.2017.02.003. 
Furnham, A. (2005). Spare the rod and spoil the child lay theories of corporal punishment. New Haven \& London, EN: Yale University Press.

Gershoff, E. T., \& Grogan-Kaylor, A. (2016). Spanking and child outcomes: Old controversies and new meta-analyses. Journal of Family Psychology, 30(4), 453469. doi:10.1037/fam0000191.

Gibson, C. L., \& Fagan, A. A. (2018). An individual growth model analysis of childhood spanking on change in externalizing behaviors during adolescence: A comparison of whites and african americans over a 12-year period. American Behavioral Scientist, 62(11), 1463-1482.

doi:10.1177/0002764218793689.

Heilmann, A., Kelly, Y., \& Watt, R. G. (2015). Equally protected? $A$ review of the evidence on the physical punishment of children. Edinburgh, SC: NSPCC Scotland.

Ho, K. (2019, Juli 4). Indonesian parents split on criminalising corporal punishment. Yougov id. Retrieved from https://id.yougov.com/id/news/2019/07/04/i ndonesian-parents-split-criminalisingcorporal-pu/.

[Kemen PPPA] Kementerian Pemberdayaan Perempuan dan Perlindungan Anak Republik Indonesia. (2020). Sistem Informasi Online Perlindungan Perempuan dan Anak (SIMFONI-PPA). Retrieved from https://kekerasan.kemenpppa.go.id/ringkas an.

Kish, A. M., \& Newcombe, P. A. (2015). "Smacking never hurt me!" Identifying myths surrounding the use of corporal punishment. Personality and Individual Differences, 87, 121-129. doi:10.1016/j.paid.2015.07.035.

Kitano, N., Yoshimasu, K., Yamamoto, B. A., \& Nakamura, Y. (2018). Associations between childhood experiences of parental corporal punishment and neglectful parenting and undergraduate students' endorsement of corporal punishment as an acceptable parenting strategy. PLOS ONE, 13(10), $1-16$. doi:10.1371/journal.pone.0206243.

Kuhl, D. C., Warner, D. F., \& Wilczak, A. (2012). Adolescent violent victimization and precocious union formation. Criminology, 50(4), 1089-1127. doi:10.1111/j.1745-9125.2012.00288.x.

Malherek, M. N. (2016). The prevalence and predictors of parental corporal punishment in the United States (Tesis). Southern Illinois University Edwardsville, Illinois, Amerika Serikat. Retrieved from https://search.proquest.com/openview/b88 983c507f86d8dae13c6027eea7e64/1 ?pqorigsite $=$ gscholar $\& \mathrm{cbl}=18750 \&$ diss $=y$.

Maryam, S. (2017). Gambaran pendidikan orang tua dan kekerasan pada anak dalam keluarga di Gampong Geulanggang Teungoh Kecamatan Kota Juang Kabupaten Bireuen. Gender Equality: International Journal of Child and Gender Studies, 3(1), 69-76.

Mehlhausen-Hassoen, D. (2019). Genderspecific differences in corporal punishment and children's perceptions of their mothers' and fathers' parenting. Journal of Interpersonal Violence, $00(0), 124$. doi:10.1177/0886260519842172.

Nielsen Company. (2017). New approach for indonesia socio economic status. Retrieved from https://idoc.pub/documents/nielsen-newapproach-for-indonesia-socio-economicstatus-to-share-jlk9yy0z5z45.

Piché, G., Huỳnh, C., Clément, M. È., \& Durrant, J. E. (2017). Predicting externalizing and prosocial behaviors in children from parental use of corporal punishment. Infant and Child Development, 26(4), 1-18. doi:10.1002/icd.2006.

[RI] Republik Indonesia. (2014). UndangUndang Republik Indonesia Nomor 35 Tahun 2014: Perubahan atas UndangUndang Nomor 23 Tahun 2002 tentang Perlindungan Anak (Lembaran Negara Republik Indonesia Tahun 2014 Nomor 297). Jakarta, ID: RI.

Sherbert Research. (2007). A study into children's views on physical discipline and punishment. DCSF and COI. Retrieved from

https://dera.ioe.ac.uk/6886/9/Section\%205 8\%20Children\%20and\%20Young\%20Peo ple\%20Survey.pdf.

Simons, D. A., \& Wurtele, S. K. (2010). Relationships between parents' use of corporal punishment and their children's endorsement of spanking and hitting other children. Child Abuse and Neglect, 34(9), 639-646. doi:10.1016/j.chiabu .2010.01.012.

Straus, M. A. (2010). Prevalence, societal causes, and trends in corporal punishment 
by parents in world perspective. Law and Contemporary Problems, 73(2), 1-30.

Straus, M. A., Hamby, S. L., Finkelhor, D., Moore, D. W., \& Runyan, D. (1998). Identification of child maltreatment with the parent-child conflict tactics scales: Development and psychometric data for a national sample of American parents. Child Abuse and Neglect, 22(4), 249-270. doi:10.1016/S0145-2134(97)00174-9.

Vittrup, B., \& Holden, G. W. (2010). Children's assessments of corporal punishment and other disciplinary practices: The role of age, race, SES, and exposure to spanking. Journal of Applied Developmental Psychology, 31(3), 211-220. doi:10.1016/j.appdev.2009.11.003.

Walker, C. S., Stearns, M., \& McKinney, C. (2018). Effect of parental corporal punishment on endorsement of its use: Moderated mediation by parent gender and attitudes toward corporal punishment. Journal of Interpersonal Violence, 00(0), 1-24. doi:10.1177/088626051881987.

Watakakosol, R., Suttiwan, P., Wongcharee, H., Kish, A., \& Newcombe, P. A. (2019). Parent discipline in Thailand: Corporal punishment use and associations with myths and psychological outcomes. Child Abuse and Neglect, 88, 298-306. doi:10.1016/j.chiabu.2018.12.002.
Wati, D. E., \& Puspitasari, I. (2018). Kekerasan terhadap anak, penanaman disiplin, dan regulasi emosi orang tua. Jurnal VARIDIKA, 30(1), 21-26. doi:10.23917/varidika.v30i1.6541.

Witt, A., Fegert, J, M., Rodens, K. P., Brähler, E., Silva, C. L. D., \& Plener, P. L. (2017). The cycle of violence: Examining attitudes toward and experiences of corporal punishment in a representative german sample. Journal of Interpersonal Violence, 00(0), 1-24. doi:10.1177/ 0886260517731784.

Wolf, S., \& Suntheimer, N. M. (2020). Predictors of parental disciplinary practices and associations with child outcomes among Ghanaian preschoolers. Children and Youth Services Review, 112, 1-41. doi:10.1016/j.childyouth.2019.104518.

Wonde, D., Jibat, N., \& Baru, A. (2014). The dilemma of corporal punishment of children from parents' perspective in some selected rural and urban communities of Jimma Zone, Oromia/Ethiopia. Global Journal of Human-Social Science: Sociology and Culture, 14(4), 16-27.

Zhai, F., Waldfogel, J., \& Brooks-Gunn, J. (2013). Estimating the effects of head start on parenting and child maltreatment. Children and Youth Services Review, 35, 1119-1129. doi:10.1016/j.childyouth. 2011.03.008. 